\title{
Using In Situ Measurements and Modelling to Effectively Manage Large Copper Sulfide Bearing Ore Stockpiles
}

\author{
A.M. Garvie SRK Consulting, Australia \\ C.M. Linklater SRK Consulting, Australia \\ R. Lestari PT Newmont Nusa Tenggara, Indonesia \\ K. McCaffery PT Newmont Nusa Tenggara, Indonesia
}

\begin{abstract}
At the Batu Hijau mine, located on Sumbawa Island, Indonesia, PT Newmont Nusa Tenggara plans to stockpile approximately $500 \mathrm{Mt}$ of copper ore, for up to 20 years. Much of the copper is present as the copper sulfide chalcopyrite. Construction of the stockpile commenced in late 2000 and as of early 2007 the pile contained regions more than $100 \mathrm{~m}$ high.

Oxidation of chalcopyrite in stockpiled ore results in reduced copper recovery during flotation. Thus, there is a need to both forecast and, ideally, reduce the extent of chalcopyrite oxidation occurring over the lifetime of the stockpile. A combined field measurement and modelling program was undertaken to; identify the main mechanisms leading to oxidation, predict rate of chalcopyrite oxidation and simulate the reduction of oxidation of alternative stockpile designs.
\end{abstract}

\section{Introduction}

The main oxidant of chalcopyrite is oxygen that is transported into the Batu Hijau stockpile from the outside. A programme of field work and modelling determined the dominant gas transport mechanisms and estimated rates of oxidation within the Sejorong stockpile. At or close to heap batters:

- Convection is an important gas transport mechanism.

- Oxidising regions may extend lateral distances of 50 to $200 \mathrm{~m}$ into the pile.

- Estimated oxidation rates were $4 \times 10^{-8}$ to $8 \times 10^{-8} \mathrm{~kg}\left(\mathrm{O}_{2}\right) \mathrm{m}^{-3} \mathrm{~s}^{-1}$.

Far from batters:

- The dominant oxygen supply mechanism is diffusion.

- Oxidising regions are restricted to near the top surface.

The numerical model, SULFIDOX, was able to reproduce observed stockpile characteristics, including oxygen concentrations and temperature distributions. The SULFIDOX model was used to project forwards and estimate the extent and distribution of oxidation in the stockpile over time. Calculations suggest that up to 35 to $40 \%$ of the chalcopyrite in the Sejorong stockpile could oxidise over a 20 year period.

SULFIDOX projections have been tested by continued comparison with field measurements and by undertaking examination of acid soluble copper content of stockpile-derived ore. Acid soluble copper is a measure of the presence of secondary copper precipitates (products following oxidation). To date (3 years on) these comparisons have been in relatively good agreement.

The model forecasts have been used as a tool for predicting expected future oxidation level of ore. Oxidation of stockpiles of different design were predicted with SULFIDOX and recommendations were made for management and construction strategies that could reduce the fraction of chalcopyrite oxidised. 


\section{Sulfide oxidation}

The operating strategy at Batu Hijau is to mine ore at a rate that exceeds milling capacity. Higher grade ore is fed to the mill while lower grade ore is stockpiled for reclaim and processing throughput and later in mine life. This approach was adopted to optimise life of mine project economics.

During the lifetime of a stockpile, ore material undergoes weathering and oxidation. As a result of weathering, breakdown of sulfide minerals will take place along with dissolution of gangue minerals, secondary mineral formation and transport of oxygen, water and solutes within the stockpile. Oxidation products such as brochantite $(\mathrm{Cu} 4(\mathrm{OH}) 6 \mathrm{SO} 4)$ and iron-sulfate are present on the surface of oxidised copper minerals (Figure 1), and also mobilised as copper and iron sulfate products. As $\mathrm{pH}$ increases in the dry season, ferric iron precipitates within the stockpile, while copper ions exiting the stockpile precipitate in seepage water pathways. This precipitate is identified by the characteristic green blue colour of copper minerals (e.g. sulfates, carbonates and hydroxides). An example of this phenomenon is shown in Figure 2.

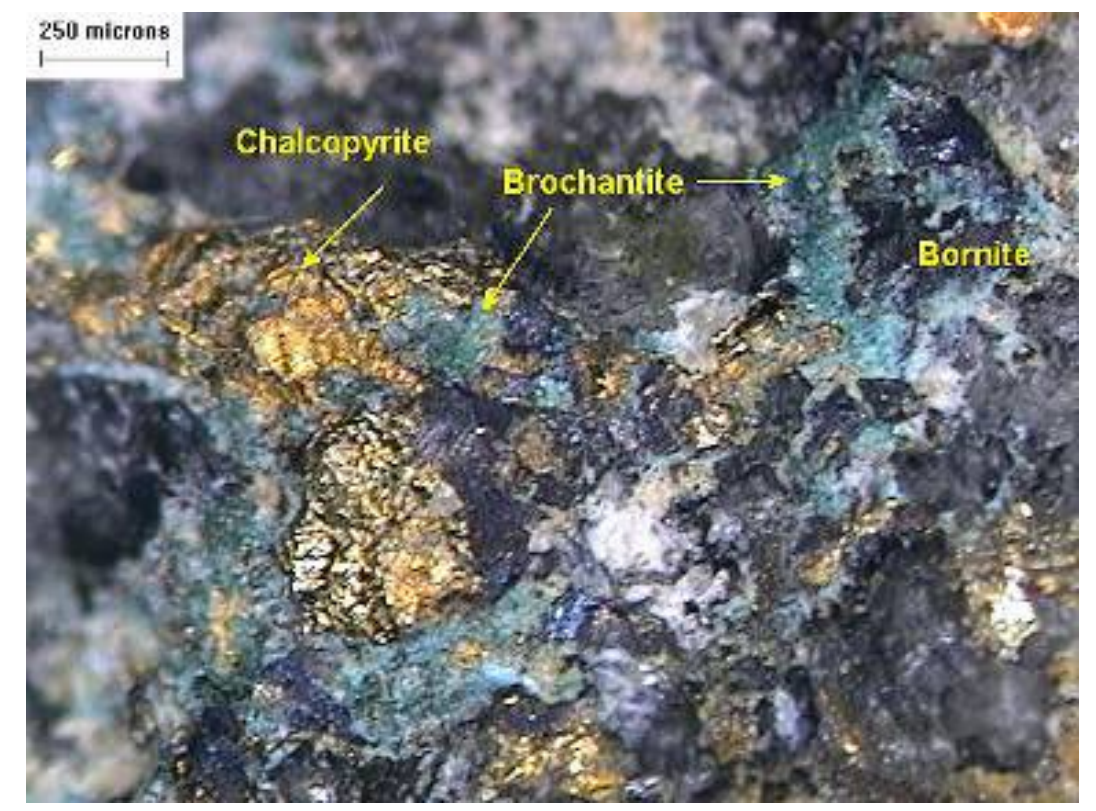

Figure 1 Brochantite is locally precipitated on the surface of chalcopyrite and bornite on stockpiled ore sample

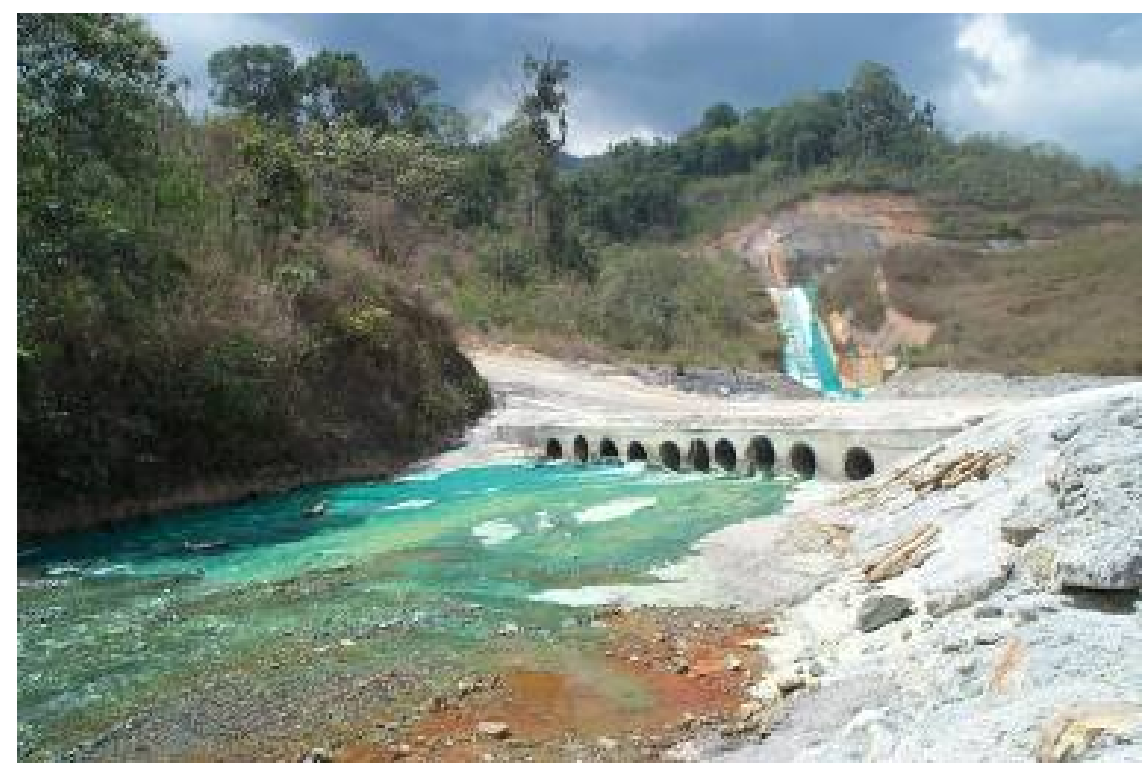

Figure 2 Stockpile seepage water pathway 
Important reactions contributing to the weathering process in the stockpile are likely to be the two oxidation reactions:

$$
\begin{aligned}
& 2 \mathrm{FeS}_{2} \text { (pyrite) }+7 \mathrm{O}_{2}+2 \mathrm{H}_{2} \mathrm{O} \rightarrow 2 \mathrm{Fe}^{2+}+4 \mathrm{H}^{+}+4 \mathrm{SO}_{4}{ }^{2-} \\
& \mathrm{CuFeS}_{2} \text { (chalcopyrite) }+4 \mathrm{O}_{2} \rightarrow \mathrm{Cu}^{2+}+\mathrm{Fe}^{2+}+2 \mathrm{SO}_{4}{ }^{2-}
\end{aligned}
$$

Both of the above reactions consume oxygen and are exothermic. Heat generation and consequent temperature gradients can develop in the stockpile and influence gas transport mechanisms and rates. There are two types of mechanism that can transport significant quantities of oxygen from the surface to the interior of a stockpile. They are diffusion and convection/advection. The distribution of oxidising material within a stockpile depends on, amongst other things, the intrinsic oxidation rate (IOR) of the ore, history of the stockpile and rate of supply of oxygen to the interior of the stockpile. IOR depends on the characteristics of the sulfides and the conditions they are subject to such as oxygen concentration and temperature.

Oxidation of chalcopyrite contained in stockpiled ore results in reduced copper flotation recovery (Lestari et al., 2008). Reducing the extent of chalcopyrite oxidation before ore processing has potential to (i) improve copper recovery and (ii) reduce net loss of copper from the stockpile due to transport of dissolved copper in effluents. To understand better the evolution of oxidation in sulfide-bearing stockpiles, a program of field work was undertaken at the Batu Hijau site to determine the dominant gas transport mechanisms and estimate rates of oxidation within the stockpile.

The field program was complemented by a modelling programme involving the numerical code, SULFIDOX. SULFIDOX was used to simulate oxidation in the stockpile, allowing forward projection to estimate future extent and distribution of stockpile oxidation. This paper describes results of the field and modelling programmes and how these have been used to support stockpile management strategies at the site.

\section{Background and methods}

\subsection{Stockpile}

Stockpile construction commenced in 2000. The northern and north eastern sides of the stockpile lie against valley walls and have no batters (see Figure 3). It is expected that at the time of stockpile construction completion a significant fraction of the stockpile will be around $100 \mathrm{~m}$ thick.

Nine probe holes were installed in the stockpile, positioned in a range of locations: on or near the batters of the stockpile, and significant distances from the batters towards the centre of the pile.

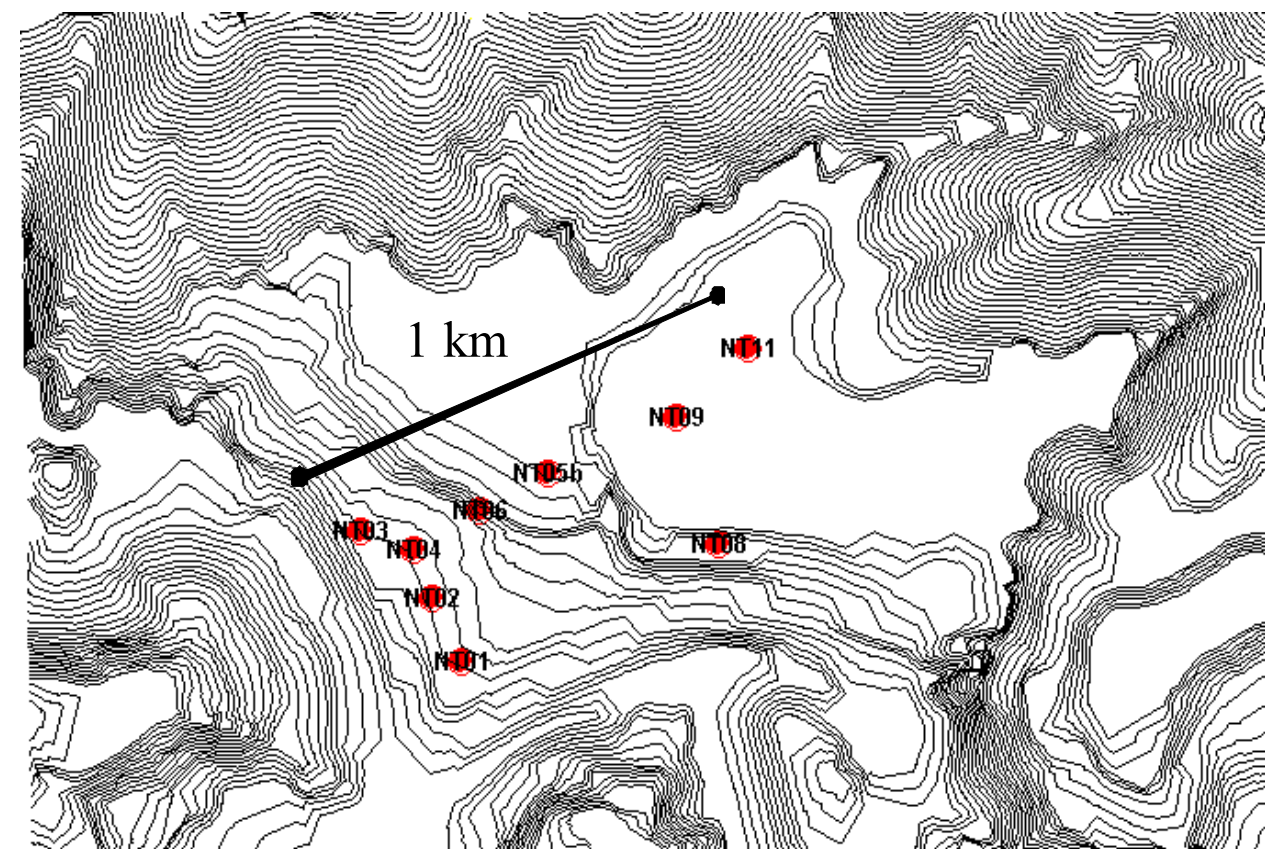

Figure 3 Plan view of the stockpile surface at the time that the field programme took place in 2004 


\subsection{Field instrumentation}

Each probe hole consisted of 21 high pressure nylon tubes and one $40 \mathrm{~mm}$ PVC pipe. The nylon tubes were of different lengths so that gas samples could be taken from up to 21 different heights within the stockpile (Figure 4). A hole was drilled (nominally $150 \mathrm{~mm}$ diameter) into the stockpile at each probe location and the tubes and pipe inserted. The space between the drilled hole and the tubes was backfilled.

Small samples of pore gas were pumped through the nylon pressure tubes to the stockpile surface and analysed using an automatic gas analyser capable of measuring oxygen concentration. Temperature was measured using a cable with 23 thermistors attached at different positions (a thermistor string) and was lowered down the inside of each probe PVC pipe.

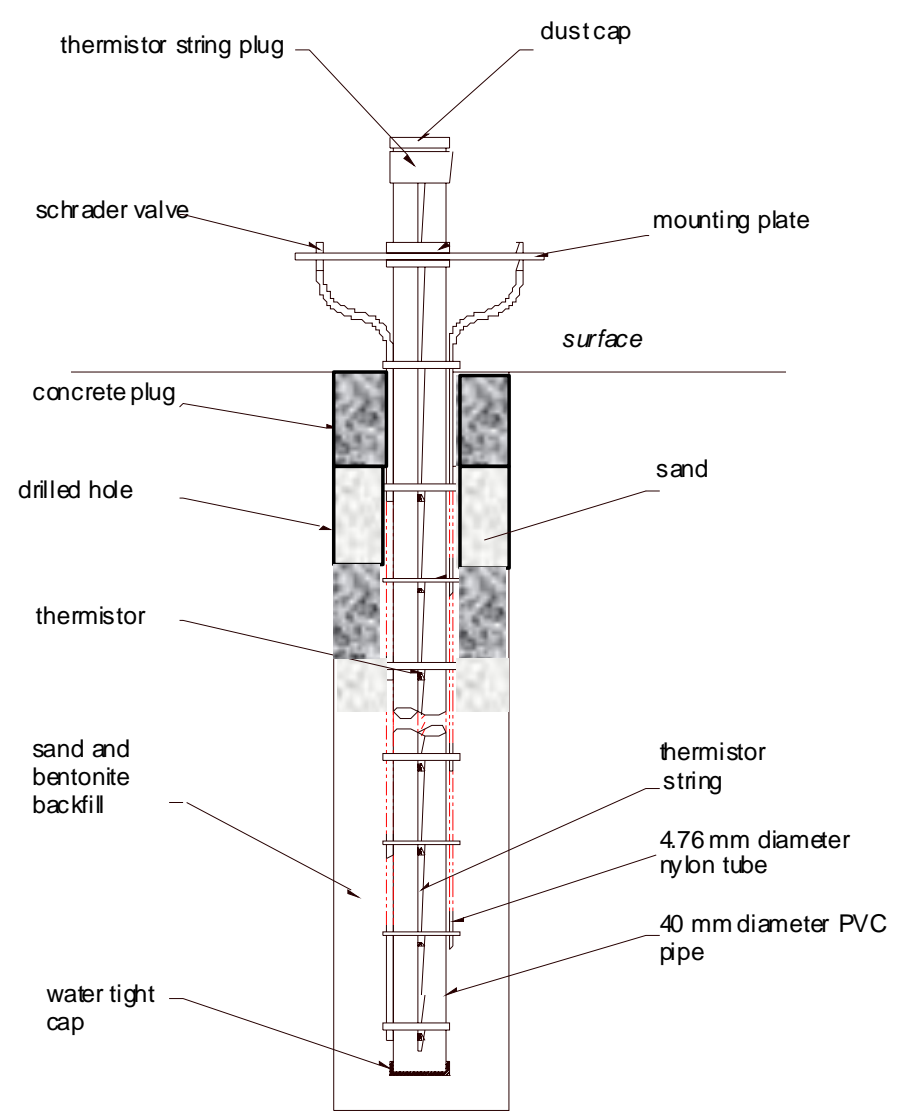

Figure 4 Schematic showing the construction of a probe hole

\subsection{Description of SULFIDOX}

SULFIDOX is a numerical code developed using a two-dimensional finite difference method. A two dimensional cross-section of the dump is defined based on a trapezoidal geometry. A computational grid is defined within the trapezoid and transport of heat, gas, and water between grid points is computed based on fundamental physics principles (Pantelis et al., 2002). In brief, SULFIDOX operates by (i) defining initial conditions at each point within the computational grid, (ii) for a specified time period, allowing transport between grid points, and (iii) redefining conditions at each grid point.

The following processes are represented by the code:

- Gas transport via diffusion and/or advection.

- Heat transport via thermal conduction and/or fluid flow.

- Infiltration of water down through the waste rock dump.

- Speciation and complexation of components within the water. 
- Dissolution of minerals in the stockpile; both slow dissolution subject to kinetic controls, and rapid 'instantaneous' dissolution subject to thermodynamic equilibrium laws.

- Precipitation of secondary minerals within the stockpile.

SULFIDOX can model the evolution of these processes temporally and spatially within a sulfidic heap in two dimensions.

\section{Results of the field measurements}

\subsection{Depth profiles: Oxygen pore gas concentration and temperature}

Oxygen concentration and temperature profiles were measured at each probe hole in February 2004, October 2005 and February 2007. Probe holes NT05, NT09 and NT11 were buried as the stockpile was enlarged and could not be accessed for measurement. An oxygen concentration profile measured in the batter during February 2004 at location NT03 and one measured in the core at NT09 are shown in Figure 5. Temperature profiles measured are shown in Figure 6.

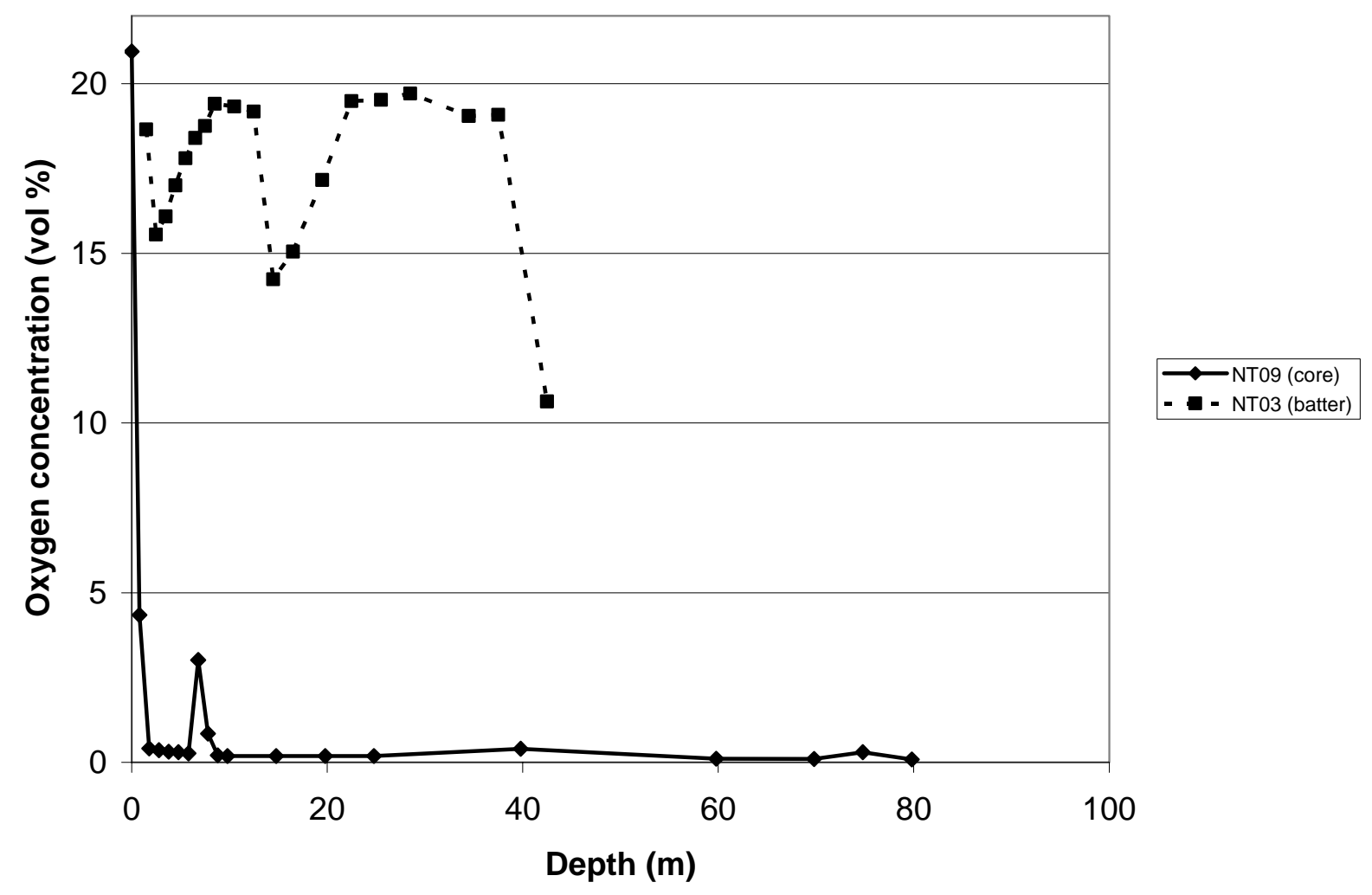

Figure 5 Oxygen concentration measured at NT03 and NT09 in February 2004 


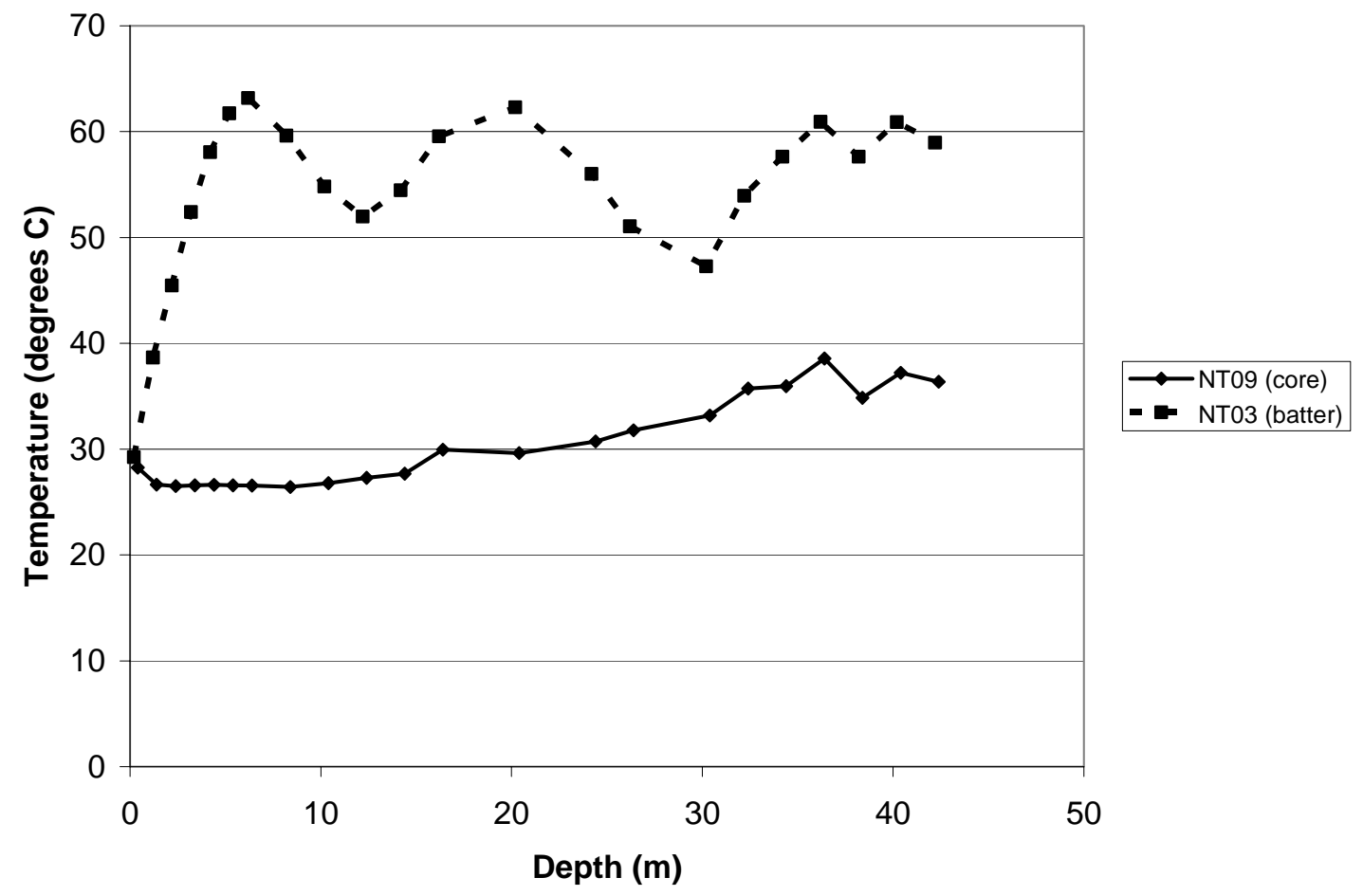

Figure 6 Temperature measured at NT03 and NT09

\subsection{Discussion}

Measured oxygen concentrations were generally higher in the batters than in the stockpile core. Oxygen concentrations were highest at NT01, NT02, NT03, NT04 and NT08. In these probe holes oxygen concentrations commonly exceed $15 \mathrm{v} \%$ at depths of greater than $30 \mathrm{~m}$.

Concentrations away from the batter at NT11 and NT09 were lowest, dropping to less than $1 \mathrm{v} \%$ within a few metres of the surface.

Oxygen concentrations along profiles in the batter were irregular. This was thought to be due to localised variations in permeability and intrinsic oxidation rate of the ore and variability in the transport of gas from the batter face to the batter interior.

Temperatures were generally higher over a broader height range nearer the batters. Maximum temperatures were also higher in the batter. For example at probe hole NT09 the minimum temperature was about $26^{\circ} \mathrm{C}$ and maximum temperature about $39^{\circ} \mathrm{C}$, whilst at NT02, NT03, NT04 and NT08 peak temperatures exceeded $60^{\circ} \mathrm{C}$. Peaks and troughs observed in batter temperatures are believed to be the result of staged construction of the stockpile.

A stockpile exhibiting high temperature and high oxygen concentration indicates that sulfide oxidation is not limited by oxygen supply. A stockpile of the same geometry that is exposed to the same ambient conditions but has lower temperature and high oxygen concentration indicates that the oxidation rate of the sulfides is lower than in the first stockpile. Low temperature and low oxygen concentration indicates an oxidation rate limited by the oxygen supply rate. In general, a stockpile may exhibit a number of these conditions depending on location in the stockpile, stage of the overall oxidation process and changes that occur such as modification of oxygen supply via application of a cover and fresh ore deposition.

In the Batu Hijau stockpile field evidence indicates oxygen is supplied by convection in the batters and that oxidation occurs throughout a large fraction of the batter material. Towards the core of the stockpile oxygen is supplied by diffusion and oxidation and is limited to locations very near the surface. Compaction of the stockpile surface due to haul truck and dozer traffic may have reduced the permeability of surface material and convective transport of oxygen away from the batter. The outcome is that diffusion was the dominant 
oxygen transport mechanism at NT09 and other locations in the core of the stockpile. Temperatures in the core region that are above the long term average temperature for the region may be due to remnant heat produced due to oxidation when the stockpile was shorter.

\subsection{Calculated oxidation rates}

In principle IOR values can be calculated from the temperature profiles. These calculations require measurement of temperatures on a number of occasions and detailed knowledge of the history of the stockpile construction and initial temperature of the stockpile material. Although the required information was not accurately known estimates of the temperature profiles were made as shown in Table 1 . The values were estimated by assuming that a slab of the stockpile had been oxidising at a constant rate for a time estimated from the record of the stockpile surface elevation history. The equation for the temperature in a heated slab with constant uniform heating (Carslaw and Jaeger, 1959) was used to calculate the expected temperature. An iterative process of choosing an IOR, calculating the temperature based on the estimated age of the slab and comparing the results with measured temperature values was used.

Table 1 Range of depths of temperature profiles used in IOR estimates and the estimated IOR values

\begin{tabular}{ccc}
\hline Probe Hole ID & Depth Range (m) & $\mathbf{1 0}^{-\mathbf{8}} \mathbf{x}$ Estimated IOR $\left(\mathbf{k g}\left(\mathbf{O}_{\mathbf{2}}\right) \mathbf{m}^{-\mathbf{3}} \mathbf{s}^{\mathbf{- 1}}\right)$ \\
\hline NT01 & $0<\mathrm{x}<30$ & 4 \\
NT02 & $0<\mathrm{x}<20$ & $4<$ IOR $<8$ \\
NT03 & $0<\mathrm{x}<22$ & $6<$ IOR $<7$ \\
NT05 & $0<\mathrm{x}<30$ & 6 \\
\hline
\end{tabular}

The values determined from the temperature profiles are similar to values determined in earlier column studies of stockpile ore (Brown et al., 2000) that ranged between $2 \times 10^{-8}$ to $9.2 \times 10^{-8} \mathrm{~kg}\left(\mathrm{O}_{2}\right) \mathrm{m}^{-3} \mathrm{~s}^{-1}$.

\section{SULFIDOX modelling}

The SULFIDOX model requires that initial physical and chemical properties of the stockpile be quantified in some detail. Some key input parameters used are given in Table 2. Wherever possible input values were based on measured material characteristics. As noted above, some stockpile properties were estimated where no direct measured data were available.

Table 2 Key SULFIDOX input parameters

\begin{tabular}{lccc}
\hline & Region 1 & Region 2 & Region 3 \\
\hline & $\begin{array}{c}\text { Main body of } \\
\text { stockpile }\end{array}$ & $\begin{array}{c}\text { Compacted } \\
\text { surface }\end{array}$ & $\begin{array}{c}\text { Compacted rind } \\
\text { (theoretical design } \\
\text { only) }\end{array}$ \\
\hline Bulk density, $\mathrm{kg} \mathrm{m}^{-3}$ & 1900 & 1900 & 1900 \\
Intrinsic coefficient of medium permeability, $\mathrm{m}^{2}$ & $5 \times 10^{-9}$ & $1 \times 10^{-10}$ & $1 \times 10^{-10}$ \\
Porosity (occupied by water and gas) & 0.3 & 0.27 & 0.27 \\
Water infiltration, $\mathrm{m} \mathrm{yr}^{-1}(10 \%$ annual rainfall) & 0.3 & 0.3 & 0.3 \\
Water content, vol\% & 5 & $5^{\mathrm{a}}$ & $5^{\mathrm{a}}$ \\
IOR, $\mathrm{kg}\left(\mathrm{O}_{2}\right) \mathrm{m}^{-3} \mathrm{~s}^{-1}$ & $6 \times 10^{-8}$ & $6 \times 10^{-8}$ & $2 \times 10^{-8}$ \\
Chalcopyrite content, $\mathrm{wt}^{-8} \%$ & 1.0 & 1.0 & 0.6 \\
Pyrite content, $\mathrm{wt} \%$ & 0.1 & 0.1 & 0.3 \\
\hline
\end{tabular}


Two heap configurations were modelled:

- Base model - this heap was configured to be representative of the existing stockpile. The main body of the heap was assumed to be relatively homogenous, but the top surface (due to movements of truck traffic, etc.) was assumed to be compacted.

- Proposed alternative heap design - The alternative design (Figure 7) includes the following characteristics, intended to control and minimise oxidation in the stockpile:

o Large geometry - the larger the stockpile, the greater the distances over which oxygen must travel in order to maintain oxidation in the core regions of the pile.

o A compacted top surface to reduce permeability and thus oxygen ingress.

o A compacted 'rind' around the outside of the stockpile constructed of low grade or waste material. The rind reduces oxygen ingress through the batters of the pile to protect inner, higher value ore.

\section{REGION 2}

Compacted top surface

$1 \mathrm{~m}$ thick

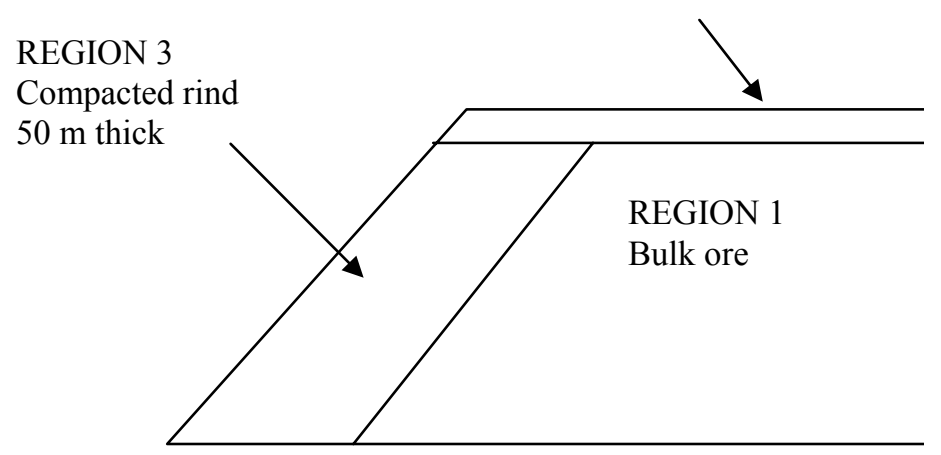

Figure 7 Proposed alternative heap design 

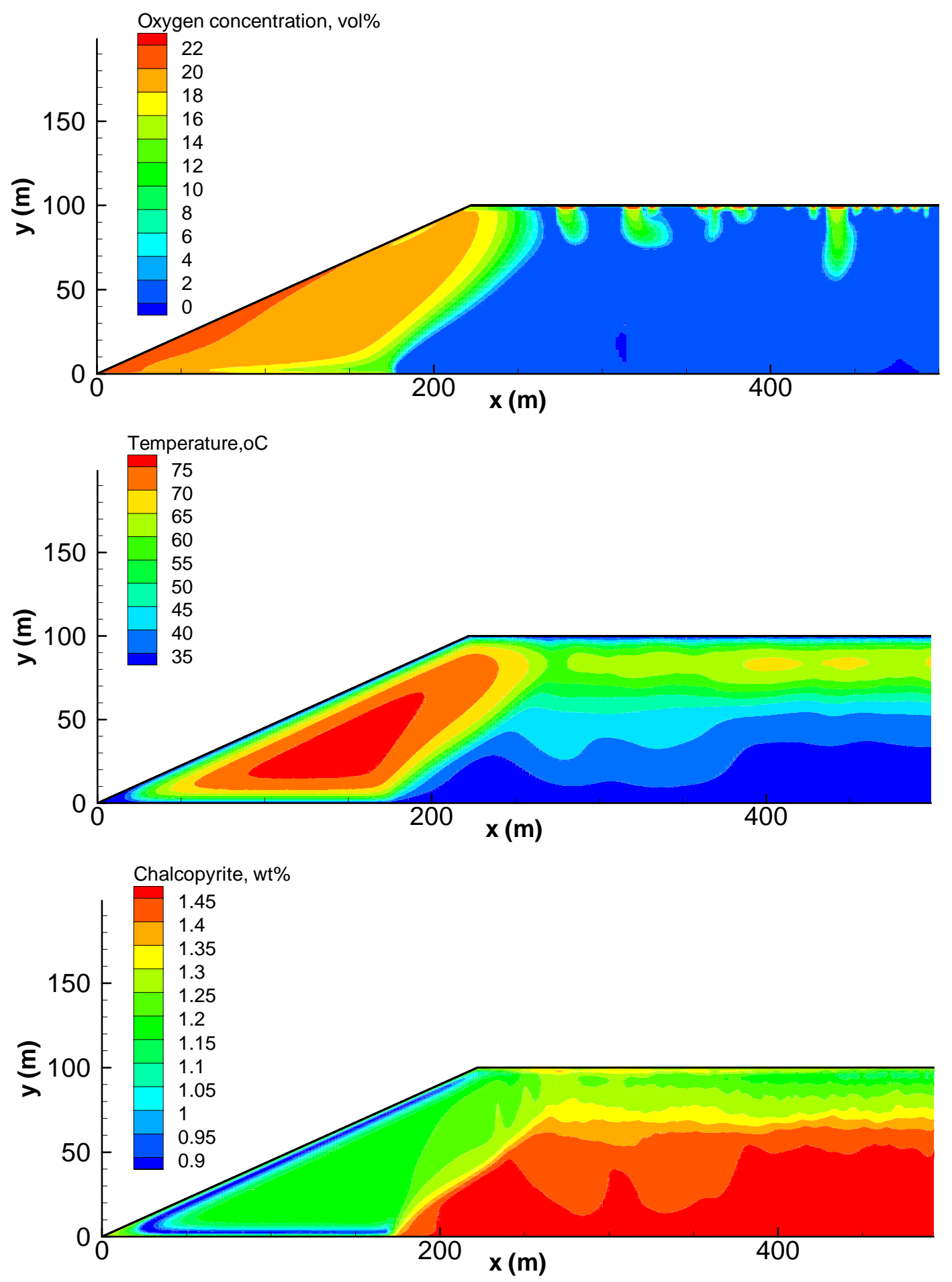

Figure 8 SULFIDOX output (Base model): Calculated two-dimensional distribution of (i) oxygen pore gas concentration, (ii) temperature and (iii) chalcopyrite content, after 4 years of oxidation

Figure 8 illustrates model output for the base model. The model was able to reproduce observed stockpile characteristics, for example:

- High concentrations of oxygen in heap batters and more limited distribution of oxygen in the internal volumes of the stockpile. This behaviour is consistent with measured profiles of oxygen pore gas concentration as illustrated in Figures 5 and 6. 
- Significantly elevated temperatures, up to $75^{\circ} \mathrm{C}$. Several of the measured temperature profiles showed temperatures of up to $65^{\circ} \mathrm{C}$.

- Significant oxidation of chalcopyrite in some regions of the stockpile. The occurrence of oxidation has been established by field observation, mineralogical studies and monitoring the proportion of 'acid soluble copper' present in stockpiled ore that reports to the flotation plant (Lestari et al., 2008).

Having established that the model was capable of reproducing the current behaviour of the stockpile, it was used to predict the future extent and distribution of oxidation. These predictions were compared with similar projections for the proposed alternative heap design (Figure 9). Compared to the base design, the alternative heap design is associated with a significant reduction in expected progress of oxidation; by 20 years, only $15 \%$ of the chalcopyrite has oxidised compared to about $35 \%$ for the base case.

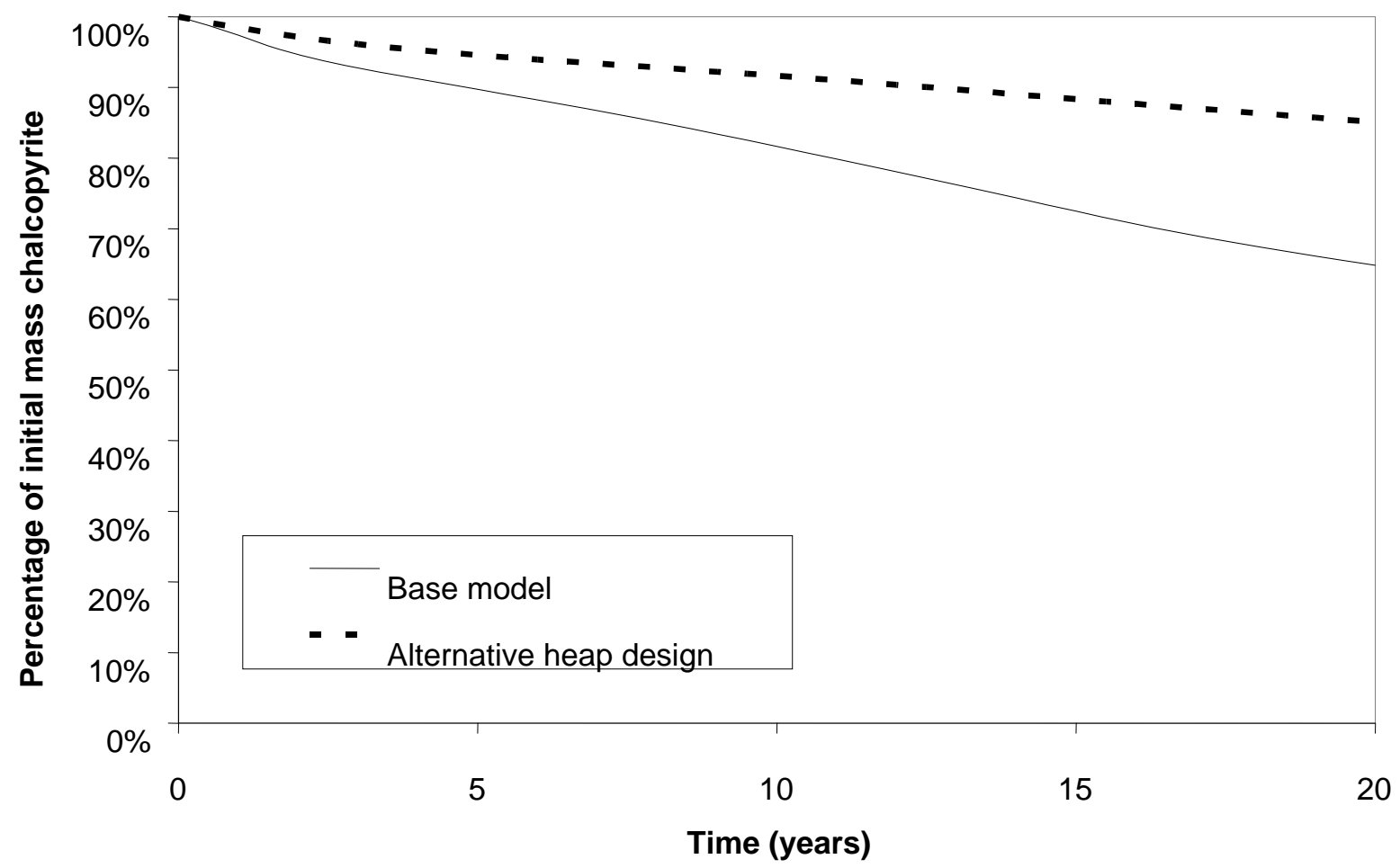

Figure 9 Progress of oxidation for the base and proposed alternative stockpile design. The calculated amount of chalcopyrite in the stockpile is shown, presented as a percentage of the initial mass

Due to limited space around the existing stockpile the addition of a compacted rind was not practical. However, the predicted rate of oxidation of the chalcopyrite supported an approach to management of overall copper that included (1) augmenting the flotation process with controlled potential sulfidisation (via hydrosulfide) and (2) use of a treatment plant to recover copper from stockpile seepage.

\section{Conclusions}

With respect to the Batu Hijau stockpile, the main conclusions from this study are:

- Convection is the dominant gas transport mechanism in the stockpile batters. Convection may also be a dominant gas transport mechanism in some regions of the stockpile away from the batters.

- The intrinsic oxidation rates determined from temperature measurements within the stockpile ranged from $4 \times 10^{-8}$ to $8 \times 10^{-8} \mathrm{~kg}\left(\mathrm{O}_{2}\right) \mathrm{m}^{-3} \mathrm{~s}^{-1}$.

- Approximately 35 to $40 \%$ of contained chalcopyrite in the stockpile is expected to have oxidised after 20 years. 
The field and modelling programme has facilitated greater understanding of stockpiled ore oxidation behaviour. Integration of results from these studies with results of ongoing flotation recovery studies has allowed prediction of future expected oxidation level and recovery targets and development of improved stockpile management strategies.

An alternative stockpile design was shown by SULFIDOX modelling to decrease the rate of chalcopyrite oxidation of only $15 \%$ of contained chalcopyrite after 20 years compared to 35 to $40 \%$ for the base case. The alternative design could not however be implemented on site due to lack of available ground for stockpile construction. Instead, strategies to mitigate oxidation related production losses have been adopted. These include installation of controlled potential sulfidisation (CPS) flotation to facilitate oxidised sulfide copper recovery and also recovery of dissolved copper from stockpile drainage solution into saleable product (Lestari et al., 2008).

\section{References}

Brown, P.L., Comarmond, J.M. and Clark, N.R. (2000) The oxidation of sulfide sulfur in medium- and low-grade copper ore stockpiles. 1. Column study. Australian Nuclear Science and Technology Organisation ANSTO/C597.

Carslaw, J.C. and Jaeger, H.S. (1959) Conduction of heat in solids. Second Edition, Oxford University Press Inc., New York.

Lestari, R., McCaffery, K., Garvie, A. and Linklater, C. (2008) Stockpile oxidation management. Proceedings of the XXIV International Mineral Processing Congress, 24 to 28 September 2008, in preparation. Secretariat of China IMPC XXIV Organizing Committee.

Pantelis, G., Ritchie, A.I.M. and Stepanyants, Y.A. (2002) A conceptual model for the description of oxidation and transport processes in sulphidic waste rock dumps, Applied Mathematical Modelling 26, pp. 751-770. 